\title{
LA NECESIDAD DEL ESTADO SOCIAL DE DERECHO PARA EL FORTALECIMIENTO DE LA DEMOCRACIA EN LA COYUNTURA COLOMBIANA
}

\author{
Irina Alejandra Junieles Acosta \\ Advogada pela Universidad de Cartagena \\ e especialista em Ética e Filosofia Política pela Universidad de Cartagena
}

E-mail: irinajunieles@hotmail.com

\section{Resumen}

En Colombia para que exista una democracia participativa real, en la coyuntura actual de la aplicación del modelo económico neoliberal, se requiere la garantía de los derechos sociales en el marco del Estado Social de Derecho, que permita a todos los ciudadanos y las ciudadanas ejercer sus derechos fundamentales en condiciones de igualdad real, constituyendo una sociedad civil fuerte que incida en las decisiones que toman los gobernantes y que ofrezca legitimidad a las normas jurídicas.

Palabras claves: democracia participativa; derechos sociales; Colombia

a década de los noventa trajo para los países de América Latina

la profundización de los procesos de liberación de sus economías y su entrada, tardía y como actores de segundo orden, a la ola de la globalización. Colombia no escapó a los influjos de esta dinámica y al comenzar la presente década el país se enrumbó en un rápido proceso de liberalización económica, respaldada por importantes cambios políticos que se concretaron en la Constitución de 1991.

Las transformaciones políticas más importantes fueron de un lado la instauración del Principio Democrático en virtud del cual las ciudadanas y ciudadanos tendríamos amplios espacios de acción para la discusión y decisión de los asuntos que nos competen tales como una injerencia directa en la decisión, ejecución y control de la gestión estatal en sus diversos niveles de gobierno y un revaloración del 
concepto de soberanía popular, en virtud del cual, entre gobernantes y gobernados se establece una relación más íntima, toda vez que éstos "participan" activamente en la gestión de aquellos.

De otro lado, la consagración en el texto superior del Estado Social de Derecho, que a groso modo, se haya diferenciado del Estado de Derecho en que ambos cumple la función de sujetar a las ciudadanas y ciudadanos a la ley, pero el primero debe garantizar las condiciones mínimas para que las personas ejerzan sus libertades, vigilando que el ejercicio de los derechos liberales por parte de algunos no atenten contra los derechos fundamentales, sociales, económicos y culturales de los otros (Perez, 1995) ${ }^{`}$.

El Estado Social de Derecho busca 1) defender la autonomía del individuo frente a la arbitrariedad pública y privada; 2) promover la participación real y efectiva de las personas en las decisiones políticas o sociales que las afectan y, 3) procurar las condiciones materiales que permitan la mínima igualdad necesaria para que las personas puedan, realmente, ser libres (Garcia et al., 1997).

Es patente que entre estas premisas, el Principio Democrático, el Estado Social de Derecho y la aplicación de políticas de corte Neoliberal surgen incompatibilidades centradas principalmente en que el neoliberalismo pretende la reivindicación de los derechos liberales de una forma independiente a sus resultados.

Los cambios económicos han estado soportados desde los noventa hasta la fecha, sobre una premisa que Jorge Child sintetizaba así: "Lo que el mercado decida, con las fuerzas dadas que dominan su oferta y su demanda, es la racionalidad social y el equilibrio absoluto del sistema"(Child, 1994, p.15). En el caso colombiano se optó por la receta de un nuevo Estado encargado de perfeccionar el régimen capitalista de competencia abierta y al cabal cumplimiento de su rol de racionalizador del interés colectivo y servidor social de última instancia .(Garay, 1995, p.145).

\footnotetext{
I José Luis Monereo Pérez define el Estado de Bienestar como "una forma de organización del poder político en la comunidad que comporta una responsabilidad de los poderes públicos en orden a asegurar su protección social y bienestar básico para sus ciudadanos. Implica la provisión pública de una serie de servicios sociales, incluyendo transferencias para cubrir necesidades humanas básicas de los ciudadanos de una sociedad compleja y cambiante y la responsabilidad estatal en el mantenimiento de un nivel mínimo de vida a todos los ciudadanos pertenecientes a la comunidad política.
} 
Sin embargo, dice el autor, en Colombia se aplicó el modelo como una simple receta para la restauración de un capitalismo en crisis, por lo cual se presentó con las credenciales del capitalismo salvaje, que

"sacrifica la atención a las demandas básicas de la población y el bienestar de los trabajadores por la concentración especulativa del capital. Esto representa un regreso al capitalismo de la primera revolución industrial y a la doctrina del Laisser - Faire." (Ibid., p.17)

Tales planteamientos pueden ser puestos seriamente en cuestión en términos de aceptabilidad ética y política (Sen, 1998), a esta conclusión se llega rápidamente al analizar los altos índices de acumulación de capital financiero en manos de grandes grupos transnacionales (en manos de pocos) y los altos niveles de pobreza en que se sumen los colombianos y las colombianas. Las estadísticas oficiales de la CEPAL muestran que en Colombia el porcentaje de hogares bajo la línea de pobreza aumento de $35 \%$ en 1990 a un 39\% en 1997, mientras los hogares bajo la línea de indigencia aumentaron del $12 \%$ al $15 \%$ en la misma época (Cepal, 2000).

Esta situación es especialmente grave en algunas zonas del país como la Costa Caribe en donde las condiciones de miseria de la población ( $15.53 \%$ ) corresponden al doble del porcentaje nacional $(7.23 \%$ ) y aun más grave en el Departamento de Bolívar donde la tasa de miseria es del $21.07 \%$, por lo que triplica las estadísticas nacionales (Montaño, 1998). Para el año 1997, el 63.43\% de la población de la región Caribe estaba por debajo de la línea de pobreza, situación que hoy ha aumentado en razón de las migraciones internas producto del desplazamiento violento de las comunidades campesinas hacia las cabeceras municipales y los grandes centros urbanos costeños.

\section{Estado social de derecho?}

Desde hace algún tiempo, los teóricos modernos europeos y norteamericanos vienen planteando la crisis del Estado de Bienestar, las principales criticas que se le hacen tienen que ver con el paternalismo que supone la garantía de derechos sociales a los ciudadanos y ciudadanas y que en términos de Jurgen Habermas pueden significar la 
aceptación para estos últimos de un papel que se reduce a "relaciones de clientela con unas administraciones que otorgan sus prestaciones en términos paternalistas" (Habermas, 1998, p.140).

Creemos que tales criterios no salen ilesos de la confrontación con la realidad del país. Frente a ella, los ciudadanos y las ciudadanas tiene la imperiosa necesidad de que el mismo Estado ayude a consolidar una sociedad con menores niveles de exclusión para sus miembros, acompañada de un proceso de ampliación de espacios democráticos y de consolidación de la sociedad civil como generadora de cambios sociales.

Desde allí recuperamos la validez de los planteamientos de Habermas en el sentido de construir una democracia deliberativa en que la sociedad civil ocupe un papel tan determinante que no requiera del apoyo de la institucionalidad estatal. Sin embargo en la coyuntura colombiana es imposible hablar siquiera de sociedad civil organizada, aunque los medios de comunicación pretendan hacer aparecerla en cabeza de unos supuestos representantes, cuando un alto porcentaje de la sociedad carece de los recursos elementales para la supervivencia.

Tal como lo entendemos, la función del Estado Social de Derecho impone a las instituciones la obligación de garantizar el bienestar de la población para permitir a ciudadanos y ciudadanas ejercer eficazmente todos sus derechos en situación de igualdad real.

Así, el alcance de la noción de bienestar que persigue el Estado Social de Derecho merece una especial atención. Tradicionalmente ha sido entendida desde dos puntos de vista:

a) como una lucha exclusiva contra la pobreza, es decir, el Estado se encamina a cubrir las necesidades mínimas que permitan la existencia de los ciudadanos y ciudadanas más pobres, limitando la cobertura de las necesidades a un mínimo de subsistencia² .

\footnotetext{
${ }^{2}$ Los organismos internacionales encargados de imponer los condicionalismos para la ayuda a países latinoamericanos favorecen la aplicación de políticas focalizadas de lucha contra la pobreza. Las políticas de pleno empleo, prestaciones sociales básicas universales, etc están siendo rápidamente sustituidas por otra concepción y modo de gerenciamiento en la estrategia de lucha contra la pobreza en la que se elabora un mapa de pobreza del país que refleje cuales son los grupos que se encuentran en un mayor grado de exclusión social y destinar todo el esfuerzo estatal exclusivamente a ellos.
} 
b) Como la búsqueda de la igualdad en la sociedad y no solo de lucha contra la pobreza. El interés es garantizar a la ciudadanía la realización plena y el desarrollo de sus capacidades creativas.

En la primera figura, de lo que se trata es de elaborar un mapa de pobreza del país que refleje a los grupos que se encuentran en un mayor grado de exclusión social y destinarles todo el esfuerzo estatal, es decir, que el Estado deja de ocuparse de la totalidad del universo de la pobreza para circunscribir su acción solo a los que se encuentran en el nivel mas bajo de la pirámide social; no es difícil recordar algunas políticas estatales de los noventa que se encaminaron a luchar contra la "pobreza absoluta".

La segunda forma, en cambio, predica que más que otorgar a un grupo de ciudadanas y ciudadanos unos mínimos vitales, se debe garantizar a toda la población la posibilidad de desarrollarse plenamente en la sociedad con el ejercicio de derechos sociales como la educación, la vivienda digna, la huelga, el trabajo, etc. Aquí el concepto de focalización cambia en cuanto responde a una nueva forma de análisis filosófico, social y económico de las necesidades cercano al principio de justicia equitativa como base del contrato social, que exige un tratamiento preferente a quienes más lo requieren, pero identificando como pobres a quienes tiene fallas en su capacidad para alcanzar las realizaciones básicas que quieren para su propia vida, es decir, la igualdad social no se logra sólo con la igualdad en la distribución de bienes primarios

Creemos correcta esta segunda forma de concebir el bienestar, pues implica a partir de una idea de justicia que tiende al aseguramiento de la libertad, garantizar a ciudadanos y ciudadanas el ejercicio eficaz de los derechos que los colocaran en menor grado de desigualdad social para el ejercicio de sus libertades y no simplemente la provisión de bienes materiales.

De allí que el concepto de bienestar real va ligado al de libertad real que proponemos como legitimo y se desarrolla principalmente en el ejercicio eficaz de la totalidad de los Derechos Sociales que en la Constitución colombiana están consagrados dentro del Capitulo 2 del Titulo 2. 


\section{Derechos sociales?}

La concepción de Estado Liberal desarrollada en la modernidad tiene como presupuesto básico, el respeto de aquellos derechos que cobijan a los ciudadanos y a las ciudadanas por su misma naturaleza humana.

Estos derechos, a los que hoy la tradición jurídica ha terminado por llamar Derechos Fundamentales, son producto de la evolución de los Derechos del Ciudadano proclamados en $1789^{3}$ y de la Declaración Universal de Derechos Humanos de 1948. Básicamente los derechos protegidos fueron cuatro: la vida, la igualdad, la propiedad y la libertad.

Sin embargo, el curso del tiempo ha demostrado que no basta con el respeto de los derechos liberales clásicos para lograr una sociedad justa, por el contrario, para el pleno ejercicio de la vida, la igualdad, la propiedad y la libertad, debe garantizarse también otra serie de derechos que limen las diferencias reales entre los seres humanos.

Así el Estado Social sienta sus bases en la protección de derechos que posibilitan y aseguran mediante prestaciones sociales y garantías estatales el pleno ejercicio de las libertades y en ese sentido lo entendemos como una continuación del Estado Liberal. Y digo en este sentido, porque no pretendo agotar la definición de Estado Social en la función de "procura existencial".

Creemos que lo fundamental es tratar de establecer la dimensión de la cláusula Estado Social en el marco de la Constitución de 1991, a fin de que su contenido mínimo sea preservado frente a los diferentes gobernantes y aun más frente a los funcionarios estatales con facultades legisladoras ${ }^{4}$.

${ }^{3}$ Derechos que en esta primera fase implicaron la exclusión de amplios sectores de la sociedad. Solo eran garantizados a los hombres (no a las mujeres), blancos y propietarios. Sobre este punto, Héctor Peña Díaz,(1992, p.28-29), los derechos humanos garantizados en la esfera celeste para todos los hombres en la realidad efectiva no existieron sino para unos privilegiados; los propietarios, únicos que en la práctica podían ejercer la libertad de industria, obligado tamiz para que las otras libertades fueran posibles.

${ }^{4} \mathrm{La}$ importancia del problema se hizo patente en nuestro país varias veces durante el presente año y especialmente en los últimos días por la confrontación planteada entre la obligatoriedad del aumento salarial de los empleados públicos que se deduce de una sentencia del Tribunal Constitucional, que implica la atención al principio del Estado Social de Derecho y entre la política económica de ajuste en el gasto público del gobierno que se niega a entender y atender la cláusula social constitucional. 
Pero tratar de establecer el contenido de esa regla se convierte en un destino difícil si tal como se desprende de nuestra intervención, éste no es solamente jurídico, sino que persigue la igualdad social lo que le entrega un enorme contenido político. Para lograrlo se hace necesario ahondar en la manera en que se conciben los derechos sociales.

Para ello el sistema jurídico tiene unas categorías formales que, teniendo en cuenta las garantías para su protección consagradas constitucionalmente, permiten anal:zar las normas que consagran derechos desde su positivación. Sin embargo, estas categorías resultan insuficientes en el caso colombiano porque en nuestro ordenamiento jurídico no todos los derechos fundamentales parecen gozar de la misma protección jurisdiccional y ello puede inducir a señalar que algunos derechos sociales no son fundamentales.

Efectivamente, el artículo 83 que consagra la Acción de Tutela como el principal mecanismo de garantía de los derechos, la circunscribe a la protección de los derechos fundamentales, mientras que los sociales aparecen bajo el titulo, no de fundamentales, sino de "sociales, económicos y culturales" en normas posteriores del texto constitucional.

\section{Los derechos sociales en la jurisprudencia colombiana}

La Constitución 1991 ha sido generosa en cuanto a la consagración de los derechos sociales, pues además de establecer los clásicos: salud, educación, trabajo, y seguridad social, en el citado titulo 2 capitulo 2 ha consagrado una extensa lista denominándolos "Derechos Sociales, Económicos y Culturales" entre los cuales se encuentran el medio ambiente, la democratización y promoción de la propiedad, la política cultural, científica y artística, la protección a la mujer y muchos más.

En su presentación estas normas superiores parecen no fundamentar pretensiones reclamables por la vía judicial, sino exigencias al órgano ejecutivo; pero si lo aceptáramos como cierto, negaríamos la doble dimensión de los derechos sociales: ellos constituyen normas que defienden la libertad lo que obliga a su garantía y al mismo tiempo son mandatos que obligan al Estado a proteger y actuar en favor de sus administrados. 
Este doble oficio transforma las funciones de la Justicia Constitucional en cuanto debe encargarse de la concretización jurídica de la orden constitucional frente al poder público y frente a particulares. La experiencia colombiana ha mostrado con suficiente claridad, por lo menos en el ámbito de las políticas económicas fijadas por el ejecutivo, que en Colombia la tarea de concretar la aplicación de los derechos sociales, ha correspondido casi exclusivamente a la Corte Constitucional que ha mostrado ser la única institución interesada en ponerle el hombro a la construcción del Estado Social de Derecho como reductor de desigualdades, y que al decidir Acciones de Tutela o de Inconstitucionalidad por violación o amenaza a derechos sociales, los ha desarrollado jurisprudencialmente ${ }^{5}$.

En este sentido la jurisprudencia constitucional ha sido variable. En un principio 1991-1997, la Corte no tuteló directamente los Derechos Sociales negándoles el carácter de fundamentales, pero esta posición en los tres últimos años ha dado giros sustanciales según los cuales se les entrega entidad propia a los derechos sociales como derechos fundamentales y por ende protegibles por sí mismos sin necesidad de regulación estatal. Esta teoría los hace compatibles con el concepto de derechos públicos subjetivos, es decir, aquellos que el sujeto de derecho tiene frente al Estado como representación de toda la sociedad.

Estos giros jurisprudenciales se develan al revisar, entre otras, las sentencias de tutela en las que se compromete la protección del

\footnotetext{
${ }^{5}$ La Acción de tutela es el mecanismo de protección más utilizado por los colombianos y si se examina lo que se pide en las solicitudes de tutela los resultados son impactantes. Estudios de Oscar Dueñas Ruiz, magistrado auxiliar de la Corte Constitucional y docente universitario, demuestran que desde que comenzó a operar la acción de tutela en Colombia a finales de 1991 y hasta diciembre de 1999, se han tramitado 282.072 tutelas (muchas de ellas acumulan pretensiones de decenas y centenares de personas). Es decir, que han ejercido tal acción más de un millón de colombianos. Un muestreo sobre 2375 expediente que llegaron a la Corte en 5 días $(19,22,23,24$ y 25 de noviembre de 1999) y que fueron analizados el 17 de enero del 2000 en la primera Sala de Selección de este año, prueba lo siguiente: mientras en la primera Sala de Selección de enero de 1999 el promedio de expedientes diarios que llegaba a la Corte Constitucional era de 259, en la Primera Sala de Selección del 2000 es de 475. Y las cifras ascienden: en la Sala de selección de 29 de febrero de este año se examinaron 4005 tutelas, para el 7 de marzo serán 4010, para el 14 de marzo: 4017 (correspondiente cada uno de estos grupos a 5 días hábiles, o sea, un promedio de 800 expedientes diarios).
} 
Derecho al Trabajo, al que en 1991 se le negó el carácter de fundamental pero que ante los graves casos de violación y amenaza terminó amparado dentro de los derechos de libertad e igualdad, considerándosele como dependiente de estos.

Posteriormente la Corte señaló que los Derechos Sociales son fundamentales por conexidad y se ejercen como derechos subjetivos, cuando se cumplen una serie de requisitos que las mismas sentencias señalaron. Pero avanzando aun más allá, la jurisprudencia desde mediados de 1999 viene prácticamente "constitucionalizando" o bien "fundamentalizando" un cúmulo de derechos sociales aunque no se apele directamente a las consecuencias de su doble dimensión. En ello, la Corte Constitucional ha tenido que rozar los ámbitos de la política económica del gobierno, cuando esta ha resultado contraria al espíritu democrático y social de la Constitución de $1991^{6}$.

En 1999, la Corte Constitucional estableció la inconstitucionalidad de la capitalización de los intereses hipotecarios por considerarlos contrarios a uno de los derechos sociales y económicos de los colombianos y las colombianas, el "derecho a la vivienda digna" consagrado en el Art. $51^{7}$. El Tribunal Constitucional considero que el Gobierno había impuesto medidas de carácter macroeconómico que solo perjudicaban a los deudores, haciendo que estos entregaran sus viviendas al sector financiero con su beneplácito, cuando la adquisición y conservación de la vivienda de las familias colombianas debía ser considerado una de las mayores preocupaciones del Estado. Tanto la primera como la segunda decisión obtuvieron un enorme respaldo de la sociedad civil que se había organizado para lograr el derrocamiento del sistema UPAC.

Así en el último año la Corte Constitucional viene cuestionando aspectos neurálgicos del modelo de desarrollo económico, fortaleciendo la construcción del Estado Social de Derecho.

\footnotetext{
${ }^{6}$ Rodolfo Arango señala que "la importancia de los derechos sociales fundamentales es directamente proporcional al incumplimiento efectivo de los mandatos constitucionales dirigidos al Legislador" y que "entre más demore en hacer realidad el Estado social, más poder político desplaza a los jueces constitucionales, en desmedro de la democracia. Este es el principio de inmunidad de los derechos fundamentales". ojo señalar obra citar

${ }^{7}$ Corte Constitucional Sentencias C700 y C747 Corte
} 
En sentencias de importancia histórica para el país como la C-481 de 1999, la Corte Constitucional se pronunció sobre la forma como se realiza el ejercicio de la autonomía del Banco de la República y declaró inexequible una disposición legal que le ordenaba al Banco de la República adoptar metas de inflación "... que deberán ser siempre menores a los últimos resultados registrados"8.

Aclaremos antes, que en Colombia el Banco de la República

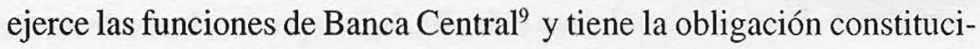
onal de velar por la capacidad adquisitiva de la moneda, lo que realiza a través de su política monetaria ${ }^{10}$. Si legalmente se obliga al Banco a mantener una inflación siempre menor al ultimo registro, el Banco estará obligado a ejercer un estricto control sobre el dinero circulante lo que puede redundar en efectos negativos sobre la actividad productiva o el llamado sector real. Es decir, por mantener estable la tasa de inflación sacrificará el aumento de la producción y muy seguramente se aumentaría el desempleo tal como ha ocurrido en los últimos años en el país.

La Corte Constitucional se da cuenta de ello y establece:

"Supongamos entonces que en una determinada coyuntura, la propia Junta llega a la convicción que, debido a que el país enfrenta una recesión muy intensa, con un alto desempleo, mientras que la inflación se ha reducido considerablemente, entonces resulta razonable adoptar una política monetaria más expansiva para reactivar coyunturalmente la economía, por lo cual considera apropiado adoptar una meta de inflación superior a la registrada en el periodo precedente. Una decisión de esa naturaleza es obviamente constitucional, por cuanto, como se explico largamente en esta sentencia el Banco de la República tiene como finalidad básica preservar la estabilidad de precios, pero no puede ser indiferente a los otros objetivos de la política económica general"."

Atrás, en la misma sentencia, la Corte estableció como marco de la política económica el mantenimiento del paradigma constitucional de Estado Social de Derecho:

\footnotetext{
${ }^{8}$ Parágrafo del Art. 2 de la Ley 31 de 1992.

${ }^{9}$ Constitución Política Capitulo VI Artículo 371.

${ }^{10}$ Recordemos que uno de los presupuestos económicos esenciales del neoliberalismo es justamente considerar el problema de la inflación como un fenómeno eminentemente monetario.

"Corte Constitucional. Sentencia C481 de 1999. El subrayado es nuestro.
} 
"Esto significa que la Constitución de 1991 no es un texto neutro que permita la aplicación de cualquier modelo económico, pues las instancias de decisión política deben de una parte respetar los limites impuestos por el conjunto de derechos, y de otra operar conforme a los valores y principios rectores que la Carta consagra, así como procurar la plena realización de los derechos fundamentales. ... En este orden de ideas, el desarrollo de las políticas monetarias, cambiaria y crediticia, constitucionalmente asignadas a la Junta del Banco de la República también se vinculan por los principios constitucionales y por la efectividad del Estado Social de Derecho".'2

Sentencias como las que venimos señalando han producido escozor en las elites económicas del país, y el rechazo hacia el organismo constitucional; apoyándose en medios de comunicación directamente vinculados a los grandes grupos económicos nacionales y transnacionales se presentó a la Corte como factor de desestabilización política ${ }^{13}$.

\section{Derechos sociales, Democracia y Sociedad Civil}

En la primera fase de este documento planteamos que la década de los noventa trajo para Colombia la implantación del sistema económico Neoliberal, pero que también supuso la consagración normativa del país como una Democracia Participativa y un Estado Social de Derecho

12 Ibid. El subrayado es nuestro.

${ }^{13}$ Hasta el momento la Corte parece permanecer incólume frente a tales criticas, sin embargo, no se puede descartar que ante el poder que ostentan las elites económicas en Colombia ocurra un cierre alrededor de la figura de la Corte que la presente opositora a los intereses de la Nación, especialmente ahora cuando varios de sus magistrados (quizá los más progresistas), terminaran su periodo constitucional. En las próximas elecciones los intereses económicos jugaran un importante papel en la elección de los miembros y los ciudadanos y ciudadanas debemos estar pendientes de quiénes son los elegidos y a qué intereses responden, a fin de salvar el que por el momento es el único instrumento institucional de defensa de los colombianos. El diario "El tiempo" editorializó el 27 de septiembre de 2000 que "Contaminada de apetitos mediáticos y tentaciones demagógicas, la Corte Constitucional ha impuesto una especie de gobierno de los jueces" y más adelante señala "Por lo pronto, lo más importante es que en la selección de los nuevos magistrados, prevista para los próximos meses, no se repitan los errores del pasado" 
Entendemos el modelo democrático participativo consagrado en la Constitución Política de 1991, como aquel en que el papel decisorio de los ciudadanos y las ciudadanas es ejercido en los espacios políticos tradicionales y en contextos más reducidos y más cercanos a las actividades diarias de las personas. La democracia, así entendida no es una simple forma de organización estatal, sino que se convierte en un proyecto político cuyo fundamento material es la dignidad humana y el respeto a la diversidad.

Pero esa democratización del Estado y de la Sociedad, que describe la Constitución, debe ir ligado a un progresivo y constante esfuerzo de construcción que no solo compromete a ciudadanos y ciudadanas sino a las instituciones públicas y a los sujetos privados que detentan posiciones de poder social o político en el Estado, pues de ello depende una mayor legitimidad en su ejercicio del poder. La manera en que las instituciones colombianas se comprometan con la realización del Estado Social de Derecho, esta íntimamente ligado con el proceso de ampliación de espacios democráticos (Habermas, 1998, p.3) ${ }^{14}$.

Sin embargo la participación de la ciudadanía y el Estado Social de Derecho se encuentra en constante tensión con la aceleración en la aplicación del modelo económico neoliberal, según el cual la sociedad se reduce a un mercado en el cual supuestamente sólo los más aptos logran sobrevivir. Las consecuencias saltan a la vista: el aumento en la brecha entre ricos y pobre, el nivel de desempleo más alto de las ultimas décadas y peores condiciones de vida para la mayoría de las colombianas y colombianos.

En 1994 Jorge Child señalaba que en Colombia las políticas neoliberales de los 90 vendrían a sacrificar la atención a las demandas básicas de la población y el bienestar de los trabajadores y trabajadoras por la concentración especulativa del capital.

La pobreza de la población colombiana en los noventa ha representado para la mayoría de los y las habitantes del país menores oportu-

\footnotetext{
${ }^{14}$ Esta relación intima sigue los planteamientos de Jurgen Habermas, quien sostiene que la legitimidad de las reglas se funda en el procedimiento democrático de producción del derecho y que entre Estado de Derecho y Democracia hay una conexión interna y conceptual que permite que los ordenes jurídicos modernos obtengan su legitimación de la idea de autodeterminación, es decir, que los ciudadanos/ciudadanas se entiendan autores de la ley cuando provenga de un consenso discursivamente alcanzado. Creemos que en nuestra realidad esta relación existe cuando se asegura hoy mediante el principio social del Estado, una cierta igualdad que permite la participación en tales espacios.
} 
nidades de participar democráticamente en la definición de su propia vida, pues se encuentran disgregados en el "sálvese quien pueda".

Así, otra consecuencia del Neoliberalismo es la fragmentación de la sociedad y ese escenario no favorece el florecimiento de practicas democráticas. Tal como lo señala Atilio Boron (1997),

\begin{abstract}
"El resultado de esta gigantesca reconversión es una sociedad que en realidad no es tal. Es una sociedad, el capitalismo neoliberal de fines de siglo XX, pero que a la vez son dos sociedades distantes, irreconciliables, extrañas- débilmente articuladas y cuya integración se produce vicariamente y de manera perversa- por la vía fetichizada e ilusoria de la televisión, que así se convierte en un factor de poder excepcional en nuestras sociedades, capaz de inventar presidentes y destrozar liderazgos que le son adversos. Una sociedad como la que hemos descrito, en donde se ha debilitado hasta grados extremos la integración social y disueltos los lazos societales y la trama de solidaridades pre-existentes es también una sociedad en donde las tradicionales estructuras de representación colectiva de los intereses populares se encuentran en crisis."
\end{abstract}

Para que en Colombia la sociedad civil pueda convertirse en gestora de su desarrollo es absolutamente necesario que el Estado garantice el pleno ejercicio de unos derechos mínimos -los fundamentales en los que se incluyen especialmente los sociales- que coloquen a los ciudadanos y ciudadanas en una menor situación de desigualdad respecto de sus semejantes.

Así, Sociedad Civil fuerte, Democracia Participativa y ejercicio efectivo de los Derechos Sociales, constituyen el ciclo en que deben comprometerse las instituciones, los ciudadanos y las ciudadanas si queremos transformar positivamente la sociedad. 


\section{Referencias Bibliograficas}

BORON, Atilio. La sociedad civil a la hora del neoliberalismo. In: Maestria en Teoria Critica del Derecho de La Universidad de Andalucia, 3., 1997, Santa Maria La Rabida. (Mimeo)

CEPAL. Estadísticas de la CEPAL. Cuadro 16: Magnitud de la pobreza y la indigencia en América Latina. Disponivel em <http://www.cepal.org >. Acesso em: 2000.

CHID Jorge. El trabajo en los noventa: rupturas y conflictos. Santa fe de Bogotá: Editorial Universidad Nacional de Colombia, 1994.

DÍAZ, Hector Peña. Luces y Sombras de los Derechos Humanos. Revista Argumentos, Bogotá, p.28-29, 1992.

GARAY Luis Jorge. América Latina frente al Nuevo entorno económico mundial. Santa fe de Bogotá: Editorial Universidad Nacional de Colombia, 1995.

GARCIA, Mauricio; BOTERO, Catalina; UPRIMNY, Rodrigo. La paz es rentable Bogotá: Universidad de los Andes, 1997.

HABERMAS, Jurgen. Facticidad y Validez. Madrid: Editorial Trotta, 1998.

MONTAÑO, Cecilia López; VIVES, Alberto Abello El Caribe Colombiano. La realidad regional al final del siglo XX. Colombia: Tercer Mundo Editores, 1998.

PÉREZ, Luis Monereo. La Política Social en el Estado de Bienestar: Los Derechos Sociales de la Ciudadanía como Derechos de Desmercantilización. Revista de Trabajo y Seguridad Social. Jul.-Sep. 1995

SEM, Amartya. Estudios económico de la pobreza, la desigualdad y el crecimiento económico. Cuadernos de Economía, Colombia, v.17, n.29, 1998.

\section{Abstract}

This is an attempt to argue in favor of social rights as essential to the building of democracy. The understanding about such case is clear: if democracy cannot be made without citizens, these must have their rights guaranteed, not only basic rights, but also the right to benefit from conditions to thoroughly exercise their citizenship in order to really participate in democracy. This issue is put more strongly amongst the Colombians due to the fragility of their civil institutions. It is based on such issue that the text is developed.

Key-words: social rights, democracy, citizenship 


\section{Resumo}

Na Colômbia, em face da vigência de um modelo neoliberal, a existência de uma democracia participativa real necessita da garantia de direitos sociais a todos os cidadãos, nos termos de um Estado Social de Direito, a fim de que os cidadãos possam exercer os direitos fundamentais em condições de real igualdade, constituindo uma sociedade civil forte que influencie as tomadas de decisões dos governantes e ao mesmo tempo assegure legitimidade às normas legais.

Palavras-chave: democracia participativa; direitos sociais; Colômbia. 